\title{
Teaching Factory-Based for Entrepreneurship Learning Model in Vocational High Schools
}

\author{
Hasanah, Muh. Nasir Malik \\ Electronics Engineering Education, Engineering Faculty \\ Universitas Negeri Makassar \\ Makassar, Indonesia \\ hasanahunm@yahoo.com
}

\begin{abstract}
The purpose of this research is to develop teaching factory-based for Entrepreneurship Learning Model in Vocational High Schools. Furthermore, the model is named "TEFA-Entrepreneurship Model". The type of research is research and development $(R \& D)$. The development process followed Plomp model development stage (1997: 5) which consists of five phases of development, namely: (1) preliminary investigation phase; (2) design phase; (3) realization/construction phase; (4) test, evaluation, revision phase; and (5) implementation phase. This research setting was in the Vocational High School in Makassar especially for Multimedia Program. The Subjects of the research were (1) principal, (b) Entrepreneurship Teachers, and (c) The 11th Grade Students of Multimedia Program. The early development of TEFA-Entrepreneurship Model has been validated by entrepreneurship experts and field practitioners, so this model is valid. The validity of the existing assessment has 5 indicators: (1) The principle of learning, (2) The Supporting Theory, (3) The Guidelines for the use of models, (4) Syntax Learning, and (5) Learning Outcomes Assessment Guidelines. The results of expert assessment and field practitioners (Vocational High School Teachers) against Entrepreneurship Model developed was valid and effective to be used in the Vocational High School.
\end{abstract}

Keywords - learning, entrepreneurship, teaching factory, TEFA-entrepreneurship model

\section{INTRODUCTION}

The Vocational education's challenge in the 4.0 industrial era is getting bigger. The rapid development of the industry is not able to be followed by the vocational education in the terms of infrastructure, facilities, technology, curriculum, and teachers' competence. As the holder of the key to success, not all of teachers are able to develop themselves with the latest knowledge and skills. As a result, the majority of graduates of vocational education are still ready to practice, not yet ready to work, with relatively low power adaptability. If this state keeps happening, the employment conditions in Indonesia would be harmed. Especially in the era of 4.0 industrial revolution nowadays, where digitization and automation are applied in all fields. Vocational training programs need to be tailored to be relevant to the 4.0 Industrial Revolution through the reconstruction of the vocational school curriculum, namely: (1) wider and new skills, and (2) using a new format in the learning process.
Vocational high school as one of the secondary educational institutions that aim to prepare middle-level manpower quality, needs to explore the potential source and its region in accordance with market needs. One of the efforts is through learning-based Teaching Factory (TEFA). Teaching Factory program is a concept of learning in Medium Vocational High School, which refers to the production-based standards and procedures in the industry and carried out in an atmosphere like that happening in the industry. Implementation of Teaching Factory vocational competence can bridge the gap between industry needs and competencies generated by the school. Teaching Factory implementation requires the involvement of the industry as an absolute relevant party to assess the quality of vocational education outcomes. Application of Teaching Factory at Vocational High School will drive mechanism of cooperation between schools and industry with mutually beneficial, so that it will always follow the development of industry automatically.

Entrepreneurship plays a major role in developing the economy, especially in reducing unemployment and poverty. Understanding the factors that can affect entrepreneurial motivation is a major and an important step in predicting and developing entrepreneurial activities. Due to economic development, entrepreneurial motivation is very important for low- and middle-income countries including Indonesia. Results of previous research found that social norms have a positive and significant impact on the motivation of secondary student entrepreneurship [1]

Entrepreneurship Education is an ability that is needed in the current era of globalization. The soul and the spirit of entrepreneurship that is formed and honed well since teens can generate innovative human resources. The necessary entrepreneurial courses are the one that have the significant impact on the increase in economic output in supporting the nation's welfare through the creation of original real work worthwhile. Continued efforts in the implementation of programs to improve the quality of vocational graduates need to be done through the implementation of Teaching Factory concept. This concept emphasizes a more demandoriented education, equip learners with the character of entrepreneurship (entrepreneurship) and involve business / industrial world as a major partner. Through Teaching Factory pattern, the optimization of educational cooperation with the industry has an impact on the learning process that is increasingly oriented to industry needs. 
Based on the Global Entrepreneurship Monitor (2016), the ranking position of Indonesian entrepreneurial intention was $25^{\text {th }}(23.2 \%)$ of total 65 Asian and Oceania countries. The number of entrepreneurial intention describes the percentage of population aged 18-64 years who are interested to open a business within the next 3 years. This organization also reported that the public perception of entrepreneurship as a good career choice was ranked $20^{\text {th }}(69 \%)$ of the 65 Asian \& Oceania countries surveyed.

Education is important in the upbringing of the entrepreneur [2]. The education and experience of an entrepreneur can provide knowledge, skills and problemsolving abilities that are transferable to many different situations.

One of the main objectives Teaching Factory vocational program is to improve the competence of vocational graduates relevant to the needs of the industry, so the impact on strengthening the competitiveness of the industry in Indonesia. Competence is delivered in an integrative manner through the implementation of Teaching Factory is competence "comprehensive" includes expertise in the realm of psychomotor, attitude and ability to think / mental (cognitive) "Higher-Order Thinking Skills" (HOTS) are able to think critically and solve problems, so that education in Vocational High Schools will produce graduates who are not only competent in terms of skills (hard skills), but also productive and do good [3].

Teaching Factory concept is defined as a learning methodology that facilitates efficient and effective learning, which adopted the practice and application-oriented training that combines learning and working environment of the atmosphere and experience realistic and relevant industry [4][5]

Several previous studies showed that students' entrepreneurial characteristics increased after participating in entrepreneurial education, such as entrepreneurship training and being engaged in business class [6] [7]

The teaching method is an important part of a learning factory to guarantee a successful learning process. In the last decade, the Teaching Factory concept has gained major interest in the academic environment ([8]

Two-way knowledge transfer channel includes two different Teaching Factory operational schemes, namely, those of the "factory-to-classroom" and the "academia-toindustry". The "factory-to-classroom" concept of the Teaching Factory aims at transferring the real production/manufacturing environment to the classroom [4]

Teaching Factory (TEFA) is a fusion of learning Competency Based Training (CBT) and Production Based Training (PBT), which learning is designed and implemented based on the procedures and standards of work actually to produce products according to market needs, so that vocational graduates are expected to compete in the era of the MEA. The concept of learning Teaching Factory cannot be separated from the concept of CBT (Competency Based Training) and PBET (Production Based Education and Training), recalled that the concept of Teaching Factory is the development of the concept of CBT and PBET to reduce the drawbacks of the concept of CBT and PBET [3]

Through the entrepreneurship education in vocational high school, learners can develop creativity and innovation to produce economic value. Learning patterns of Teaching Factory is designed based on the production of goods/services by adopting and adapting quality standards and work procedures industry, will provide a learning experience competence contingency particularly soft skills such as work ethic discipline, honest, responsible, creativeinnovative, entrepreneurial character, cooperate, compete smart and so forth. The very rare competence acquired through vocational education held in conventional, so that the attainment of expertise over to the hard skills. Therefore, the special purpose of this study resulted in Teaching Factory-based For Entrepreneurship Learning Model in Vocational High School.

\section{METHOD}

The type of research is the research and development ( $\mathrm{R}$ \& D) characteristic products. The development process followed the Plomp model in the development stage (1997: 5) consists of five phases of development, namely: (1) preliminary investigation phase; (2) design phase; (3) realization/construction phase; (4) test, evaluation, revision phase; and (5) implementation phase as follows on the Figure 1.

\section{A. Initial Investigation Stage}

This initial phase of investigation is the stage of investigation and collection of information related to entrepreneurship learning in vocational school that is applicable so far, and the job competencies required by the business world. This initial investigative phase is intended to analyze the needs of the Model developed.

\section{B. Design Phase}

The design phase aims to formulate: (1) Learning objectives; (2) develop assessment tools or instruments; (3) learning strategies to be used; (4) designing teaching modules; (5) design and carry out formative evaluation.

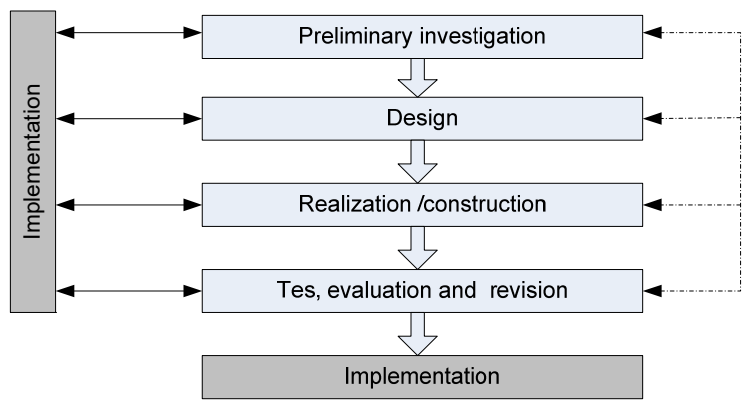

Fig. 1. The general model of educational problem solving [11]

Formative evaluation in this research is in a small group evaluation and field evaluation or product performance test. Small group evaluation or limited trial is done by piloting the program to a small group of prospective users, in this research is taken 1 class of students in the field of multimedia studies with the number of students 30 people for 1 school. This evaluation was conducted to gain input in order to improve the quality of the program. Meanwhile, field evaluation or product performance test is by taking 2 schools. 


\section{Realization Phase}

The realization phase generates the initial draft as the result of design / design, i.e the initial prototype of the Model, which includes: 1) Model Guidebook; 2) learning module; 3) Evaluation Device; and 4) research instruments. In this phase, the conceptual validation of the preliminary model prototype (expect judgment) and education practitioners on the feasibility of the prototype concept of the learning model has been developed. The criteria used for validity is to satisfy the content and construct validity assessed by educational experts and practitioners.

\section{Test, Evaluation and Revision Phase}

This phase focuses on field trials on prototype learning models as a follow-up to the results of conceptual validation by educational experts and practitioners. The activities undertaken in this phase will specifically be described in the next section that is on the product trial.

\section{E. Trial Design}

The main activity at the development stage is to conduct an empirical test of the developed model. The goal is to find out whether the developed model meets the criteria as an effective model. Prior to conducting the pilot activity, the prototype of the model and its supporting instruments, was first performed a conceptual validation by 4 (four) educational experts and practitioners, in order to know whether the model design and its supporting instruments fulfilled the validation and reliability requirements for followed up to the model trial stage. The results of the recommendations of the validator whether the model developed should still be revised or conceptually developed model that has met the valid and effective criteria.

\section{F. Trial Subjects}

The locations of the research were at the Vocational High School in Makassar for Multimedia Program. The research subjects were (1) principal; (2) the entrepreneurship teachers; (3) The 11th Grade Students of Multimedia Program.

The product performance test activities were held in 4 (four) meetings in 2 (two) schools, namely SMK Negeri 5 Makassar and SMK Muhamadiyah Makassar. The subjects of the experiments of each school consist of: (1) 11th Grade students from even semester at SMK Negeri 5 Makassar with 25 students (1 class), 1 (two) entrepreneurship teacher, and 2 (two) observers; (2) 11th Grade students of SMK Muhamadiyah Makassar with 22 students (1 class), 1 (two) entrepreneurship teachers, and 2 (two) observers.

\section{G. Data Type}

The data in this research consist of qualitative data and quantitative data. The data obtained by using two kinds of instruments, namely the instrument validation and data collection instrument instrumentation. Quantitative data include data about model quality i.e the effectiveness and implementation of the model. Qualitative data consists of competence identification data and identification of entrepreneurial learning needs in schools.

\section{H. Data Collection Instruments}

Instrument as a data collection instruments is intended to measure the validity and effectiveness of the model. The validation sheet is used to find validation of content and validation of model construction. The content validation is intended to measure the accuracy of the learning theories used in building the model. The construct validation is intended to measure consistency internally among the model components. Assessment of validated learning model developed in terms of nine aspects, namely: (1) scope of supporting theory, (2) syntax, (3) social system, (4) management reaction principle, (5) support system, (6) instructional impact and impact of accompanist, (7) implementation of learning, (8) learning environment and planning tasks, (9) evaluation. The criteria for declaring that a valid developed model is used are scoring scales: (a) invalid (value 1), (b) less valid (value 2), (c) valid (value 3 ), and (d) value 4).

The location of this research was in Vocational High Schools in South Sulawesi. The test subjects were conducted in Vocational High Schools at Multimedia and Audio-Video Technique expertise fields which have implemented The Unit Production Program well, based on observation that had been done. The Sources of data in this study were : (a) the Principal; (B) the Vice Principal; (C) Production Unit Manager; (C) Entrepreneurship Teachers; and (e) learners/students.

\section{Data Analysis Technique}

The data analysis technique used was the analysis of validity data. Categories validity of any aspect or all the aspects that the categorization criteria set by the quality of the device which was adapted from the categorization by [9] as follows on the Table I.

TABLE I. VALIDITY CATEGORIES

\begin{tabular}{|c|c|}
\hline $3.5 \leq \mathrm{M} \leq 4.0$ & category very valid \\
\hline $2.5 \leq \mathrm{M}<3.5$ & category invalid \\
\hline $1.5 \leq \mathrm{M}<2.5$ & category less valid \\
\hline $0.5 \leq \mathrm{M}<1.5$ & category invalid \\
\hline
\end{tabular}

The criterion used to decide that the instrument has a sufficient degree of validity is when the average (M) result of the assessment for the overall aspect is at least in the "valid" category. If this is not the case, a revision is required based on the validator's suggestion or by reviewing the under-valued aspects. Further re-validation and then reanalyzed. And so on until it meets the minimum average value is in a valid category. In general, the average score is analyzed by using excel program, and the evaluation between rater using SPSS program. Furthermore, to measure the inter rater reliability level on the results of the assessment / validation of research instruments by experts, analyzed by Coefficient Cohen's Kappa and Percentage of agreements statistics from Nitko and Brokhatr. The assessment sheet is said to be reliable if its reliability coefficient $(R) \geq 0.70$.

The model is said to be effective if it meets the four indicators of effectiveness: (1) increased student activity, (2) teachers' ability to manage learning at least well, (3) positive 
student and teacher responses to the developed model, and (4) increased student productivity and creativity.

\section{RESUlt AND DisCUSSION}

\section{A. Test Validity Model}

Preliminary data of this preliminary study is to describe school readiness in the implementation of Teaching Factory with 2 indicators, namely: (1) infrastructure readiness, (2) school management readiness (Principal, entrepreneurship teacher, and Production Unit manager). This is supported by the results of the Focus Group Discussion (FGD) with principals, entrepreneurship teachers and production unit managers.

The results of the FGD gave recommendation that the need to optimize the Production Unit in Vocational High School through entrepreneurial learning. Based on the needs analysis that has been implemented provide a reference to complete learning model based on Teaching Factory Entrepreneurship. The design of entrepreneurial learning model based on Teaching Factory developed in this research, called TEFA-Entrepreneurship Model. The Procedures and Design of Research and Development follow the developmental steps of Plomp, thus producing an entrepreneurship-based Teaching Factory education model in Vocational High School (TEFA-Entrepreneurship Model), as shown in Figure 2.

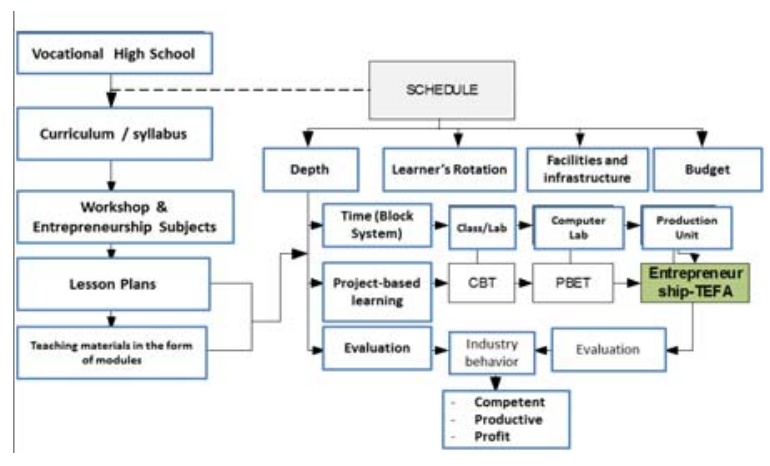

Fig. 2. Teaching Factory-based for Entrepreneurship Learning in Vocational High Schools (TEFA-Entrepreneurship Model)

The learning process of TEFA-Entrepreneurship Model that has been developed is the development of learning CBT (Competency Based Training) and PBET (Production Based Education and Training) in order to produce goods of economic value in accordance with the field of study of learners. The Learning process of TEFA-Entrepreneurship Model can be described as in Figure 3.

Teaching Factory learning process through the optimization of production units, the industry learning patterns, can produce graduates who are creative and productive. TEFA-Entrepreneurship Model is very effectively to be used in Vocational High Schools. To test the effectiveness of TEFA-Entrepreneurship Model, first validated by four experts in entrepreneurship and four field practitioners, so that the model is valid. The validity of the existing assessment criteria Model has 5 indicators, namely: (1) The principle of learning, (2) The Supporting Theory,
(3) The Guidelines for the use of models, (4) Syntax Learning, and (5) Learning Outcomes Assessment Guidelines. The results of expert assessment and field practitioners (Vocational High School Teachers) against TEFA-Entrepreneurship Model that was developed, As shown in Table II.

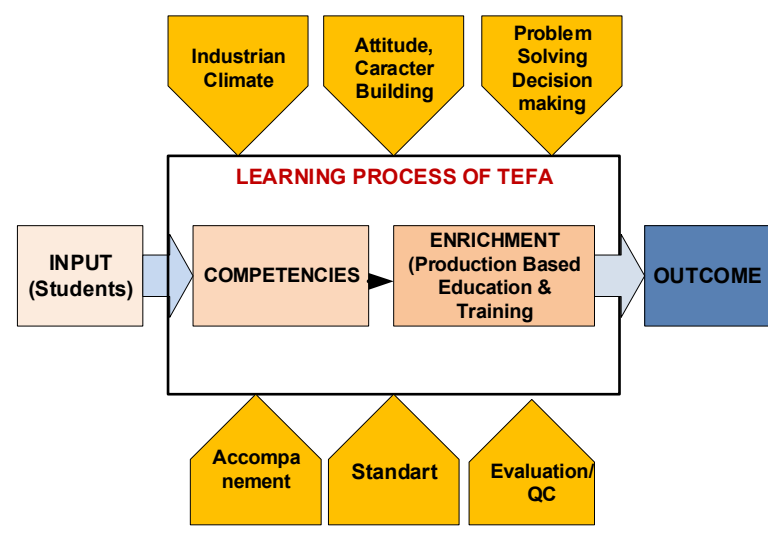

Fig. 3. Learning Process of Teaching Factory

TABLE II. RATING RESUlt OF TEFA-ENTREPRENEURSHIP MODEL

\begin{tabular}{|l|l|l|l|l|}
\hline \multirow{2}{*}{ No. } & \multicolumn{1}{|c|}{ Rated aspect } & \multicolumn{3}{|c|}{ On average Assessment Validator } \\
\cline { 3 - 5 } & Expert & Practitioners & Average \\
\hline 1 & Principles of Learning & 3.8 & 4.0 & 3.9 \\
\hline 2 & Supporting Theory Model & 4.0 & 4.0 & 4.0 \\
\hline 3 & Usage Guidelines Model & 4.0 & 3.8 & 3.9 \\
\hline 4 & syntax Learning for & 3.8 & 4.0 & 3.9 \\
\hline 5 & $\begin{array}{l}\text { Guidelines } \\
\text { Assessment of Learning } \\
\text { Outcomes }\end{array}$ & 3.8 & 4.0 & 3.9 \\
\hline 6 & $\begin{array}{l}\text { Processing stages of } \\
\text { learning outcomes }\end{array}$ & 3.8 & 3.8 & 3.8 \\
\hline & Average & 3.87 & 3.93 & 3.9 \\
\hline
\end{tabular}

Based on the results of Experts and Practitioners assessment of the TEFA-Entrepreneurship Model that was developed with 6 indicator assessment, the average expert assessment (expert entrepreneurship in college) is 3.87 are in the category of very valid, so the TEFA-Entrepreneurship Model is valid to be used as model to teach entrepreneurship in vocational school. While field practitioners' ratings average 3.93 Courses are in the Very Valid category, so the TEFA-Entrepreneurship Model is valid to be used as models to teach entrepreneurship in vocational school. So it can be concluded that the TEFA-Entrepreneurship Model development is valid to be used in Vocational High Schools.

\section{B. Model Effectiveness Test}

The model effectiveness indicators are demonstrated by the magnitude of student and teacher responses to the application of the TEFA-Entrepreneurship Model. Therefore, after the completion of the trial, students and teachers are asked to respond to the application of TEFAEntrepreneurship Model. The response results are either positive or negative. The TEFA-Entrepreneurship Model is said to be effective when users respond positively to the application of the model. Based on the results of data 
analysis of student and teacher responses to the application of TEFA-Entrepreneurship Model, it is implied that the application of the model responded very positive (good), so the model developed can be effectively used in entrepreneurial learning in vocational high school. Another indicator is that the model developed can improve students' creativity and competence.

Questionnaire responses of students in this lesson are given to 30 students with indicators: (a) is TEFAEntrepreneurship Model fun?, (b) is the Module interesting and easy to learn ?, (c) is the strategy used by the teacher in learning to encourage entrepreneurship students? (d) Is the TEFA Entrepreneurship Model able to develop students' creative ideas for starting a business?; and (h) Is the TEFA Entrepreneurship Model able to improve student competence?. Based on the results of data analysis, it is showed that TEFA-Entrepreneurship Model responded very positively by students and Teachers, so it is easily understandable and can be applied directly in business activities. Similarly, based on the observation of learning, the students are more active and creative.

The result of study in the form of portfolio showed that students' competence increases. So it can be concluded that the application of whether the TEFA-Entrepreneurship Model effectively improve the creativity and competence of vocational students. This is supported by the results of research $\lceil 10\rceil$, that TEFA-Entrepreneurship Model is effectively able to improve student competence. Graphically the results of the Model Effectiveness data analysis are presented in Figure 3 and 4.
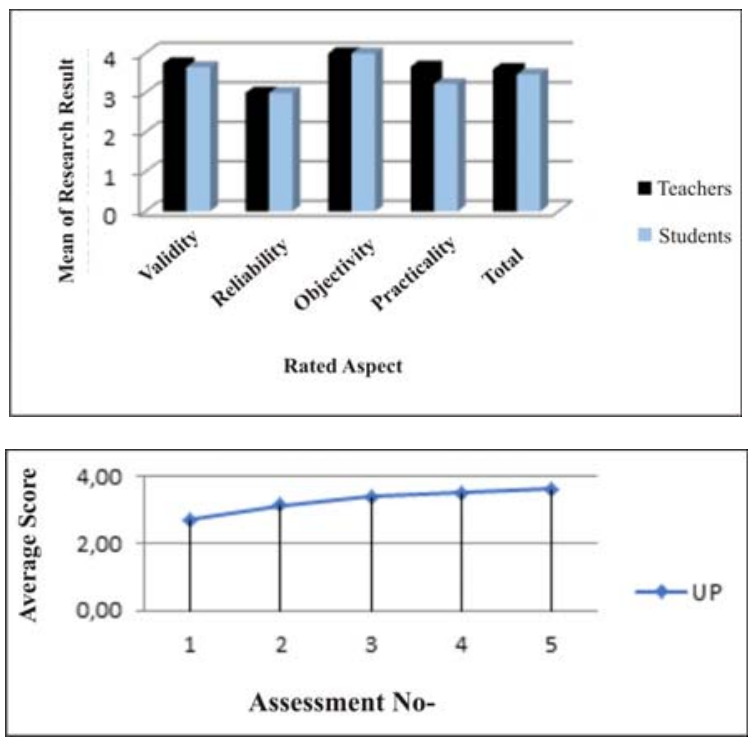

Fig. 4. Results of Analysis on Student Behavior Observation Data

Based on the results of the effectiveness analysis, it is shown that the TEFA-Entrepreneurship Model effectively improves students' creativity and competence in vocational high schools. Teaching Factory aims to communicate twoway knowledge between academia and industry. Industrybased learning paradigm or TEFA-based learning can develop students' skills based on the needs of the world of work [4]

\section{CONCLUSION}

The Procedures and Design of this Research and Development followed the development of Plomp, resulting in a Entrepreneurship Learning Model With Teaching Factory-based in Vocational High Schools (TEFAEntrepreneurship Model). The average expert assessment of the TEFA-Entrepreneurship Model development is in the category of very valid, and assessment of field practitioners to TEFA-Entrepreneurship Model development is Very Valid category, so the TEFA-Entrepreneurship Model is valid to be used as models to teach entrepreneurship in vocational high school. Teaching Factory-based for Entrepreneurship Learning Model (TEFA-Entrepreneurship Model) is valid to be used in Vocational High School.

\section{ACKNOWLEDGMENT}

The author would like to thank the Committee of APTEKINDO 2018 at Universitas Negeri Surabaya for the willingness to accept and post this article so as to be present in front of the reader. Thank you to the Directorate of Higher Education on Graduate Grant research funding so that this research can be done well. Thank you to all of those who have helped the implementation of this research so as to produce a masterpiece in the form of articles.

\section{REFERENCES}

[1] D. Purwana, “Antecedents of Secondary Students' Entrepreneurial. Motivation.," J. Entrep. Educ. (Print ISSN 1098-8394; Online ISSN 1528-2651)., vol. 21, no. 2, 2018.

[2] D. Hisrich, R.D., Peters, M.P. \& Shepherd, Entrepreneurship, Eighth Edi. Singapore: McGraw-Hill.

[3] D. VHS, Grand Design Development Teaching Factory and Technopark in SMK. Directorate General of Primary and Secondary Education Ministry of Education and Culture of the Republic of Indonesia, 2016.

[4] G. Chryssolouris, D. Mavrikios, and L. Rentzos, "The Teaching Factory: A Manufacturing Education Paradigm," Procedia CIRP, vol. 57, pp. 44-48, 2016.

[5] L. Rentzos, M. Doukas, D. Mavrikios, D. Mourtzis, and G. Chryssolouris, "Integrating Manufacturing Education with Industrial Practice using Teaching Factory Paradigm: A Construction Equipment Application," Procedia CIRP, vol. 17, pp. 189-194, 2014

[6] H. S. Rasheed, "Developing entrepreneurial characteristics in youth: The effects of education and enterprise experience," A Draft Submitt. to Int. J. Entrep. Educ., 2003.

[7] H. Chen, W., Weng, C.S. \& Hsu, "A study of the entrepreneurship of Taiwanese youth by the Chinese Entrepreneur Aptitude Scale," J. Technol. Manag. China. 5(1) p.26-39, 2010.

[8] L. U. Bozen-bolzano, D. T. Matt, E. Rauch, and P. Dallasega, "Minifactory - A Learning Factory Concept for Students and Small and medium sized enterprises," Procedia CIRP, vol. 17, no. July, pp. 178-183, 2014.

[9] Z. Azwar, "The human attitude of theory and its measurement. Yogyakarta: Student Literature.” Yogyakarta, 2010.

[10] D. H. M, "Developing a teaching factory learning model to improve production competencies among mechanical engineering students in a Vocational Senior High School," J. Tech. Educ. Train. ISSN 22298932, vol. 4, 2012.

[11] T. Plomp, Educational Design Research Educational Design Research. Netherlands: University of Twente Faculty of Educational Science and Technology Enschede. 